\title{
Approximating long-term statistics early in the Global Precipitation Measurement era
}

Thomas Stanley

Universities Space Research Association, Columbia, Maryland, USA

Goddard Earth Sciences Technology and Research, Columbia, Maryland, USA

Hydrological Sciences Laboratory, Goddard Space Flight Center, Greenbelt, Maryland, USA

Dalia B. Kirschbaum, Corresponding Author

Hydrological Sciences Laboratory

Goddard Space Flight Center

8800 Greenbelt Road

Greenbelt, Maryland, USA

301.614 .5810

dalia.b.kirschbaum@nasa.gov

George J. Huffman

Mesoscale Atmospheric Processes Laboratory, NASA Goddard Space Flight Center, Greenbelt, Maryland

Robert F. Adler

Earth System Sciences Interdisciplinary Center, University of Maryland, College Park, College Park, Maryland 


\begin{abstract}
Long-term precipitation records are vital to many applications, especially the study of extreme events. The Tropical Rainfall Measuring Mission (TRMM) has served this need, but TRMM's successor mission, Global Precipitation Measurement (GPM), does not yet provide a long-term record. Quantile mapping, the conversion of values across paired empirical distributions, offers a simple, established means to approximate such long-term statistics, but only within appropriately defined domains. This method was applied to a case study in Central America, demonstrating that quantile mapping between TRMM and GPM data maintains the performance of a real-time landslide model. Use of quantile mapping could bring the benefits of the latest satellite-based precipitation dataset to existing user communities such as those for hazard assessment, crop forecasting, numerical weather prediction, and disease tracking.
\end{abstract}




\section{Introduction}

2 Many users of precipitation data require long-term records, especially when characterizing

3 extreme events. Satellite-based precipitation estimates can meet this need in locations without

4 dense gauge networks. The National Aeronautics and Space Administration (NASA) has been

5 providing near real-time precipitation data to the community since 2002 (Huffman et al. 2010,

6 2007). The Tropical Rainfall Measurement Mission (TRMM) was launched in November, 1997.

7 Its successor, the Global Precipitation Measurement (GPM) Core Observatory, was launched in

8 February 2014 and extends observations of both falling snow and heavy to light rain past $65^{\circ} \mathrm{N}$ -

9 S (Hou et al. 2014). To provide nearly global coverage with short revisit times, the TRMM and

10 GPM missions rely on a constellation of partner satellites. The TRMM Multi-satellite

11 Precipitation Analysis (TMPA) covers the area from $50^{\circ} \mathrm{N}-\mathrm{S}$ from 2000 -present (Table 1), while

12 the Integrated Multi-satellitE Retrievals for GPM (IMERG) covers 60 N-S from March 2014-

13 present (Huffman et al. 2015).

15 Due to the use of different sensors, algorithms, and calibrations, the IMERG and TMPA products

16 differ considerably. A comparison of percentiles from 7 March 2015 to 6 March 2016 for the

17 GIS-formatted IMERG Version 3 Late run (IMERG-L) and Real-time TMPA Version 7 (TMPA-RT)

18 daily products (Huffman 2016a,b) revealed some of the characteristics of these differences

19 (Figure 1). Days with zero estimated precipitation were included in the distribution because

20 TMPA-RT and IMERG-L differ in the ability to detect very light precipitation (Hou et al. 2014). At

21 specific percentiles, the TMPA-RT values were resampled to a $0.1^{\circ}$ grid by the nearest neighbor 
22 method, then the IMERG-L values were subtracted. At the $75^{\text {th }}$ percentile (Fig 1a), there are

23 small differences between TMPA-RT and IMERG-L, but differences of more than $100 \mathrm{~mm} \mathrm{day}^{-1}$

24 at the $95^{\text {th }}$ percentile (Fig 1b). TMPA-RT tends to show heavier tropical precipitation (blue), and

25 IMERG-L tends to show heavier mid-latitude precipitation (red). In particular, the southern

26 ocean shows a large and relatively consistent difference between IMERG-L and TMPA-RT.

27 However, many locations do not fit this pattern, including some mountains and inland water

28 bodies. In addition to geographic heterogeneity, the relationship between TMPA-RT and

29 IMERG-L may vary seasonally and interannually. Combined, these factors complicate the use of

30 IMERG data in TMPA-based applications.

32 Satellite precipitation data are used in many applications such as flood monitoring, crop

33 forecasting, numerical weather prediction, and disease tracking (Kucera et al. 2013; Kirschbaum

34 et al. 2016). These user communities have relied upon TMPA data, and several workshops have

35 highlighted the need for long precipitation records (Ward et al. 2015; Ward and Kirschbaum

36 2014). While the GPM mission plans to create a consistent record of precipitation available

37 from 1998 to the present using TRMM, GPM, and partner data, this processing is not planned to 38 begin before 2018. Until that happens, application developers could take advantage of IMERG's

39 improved spatial and temporal resolution and accuracy while maintaining the benefits of

40 TMPA's long time series by adapting IMERG data to TMPA-equivalent values with quantile

41 mapping. Quantile mapping (also known as quantile matching, cumulative distribution function

42 [CDF] matching, etc.) has been used to convert gridded precipitation data to its point-based

43 equivalent (Gudmundsson et al. 2012), to adapt gridded precipitation data to a different spatial 
44 resolution (Maraun 2013), and to correct model bias at the same resolution as observational

45 data (Cannon et al. 2015). Gudmundsson et al. (2012) recommended the use of nonparametric

46 data transformations (e.g. empirical quantiles) for reducing biases across the entire distribution,

47 so these methods may be more appropriate for transforming extreme values such as rainfall

48 thresholds. An example of the statistical transformation of an empirical rainfall distribution can

49 be found in the second chapter of Some Applications of Statistics to Meteorology (Panofsky and 50 Brier 1968).

52 To demonstrate the use of IMERG in a TMPA-based application, quantile mapping from TMPA-

53 RT to IMERG-L was applied to the Landslide Hazard Assessment for Situational Awareness

54 (LHASA) model. LHASA issues a daily nowcast with a resolution of approximately 1 kilometer

55 (Kirschbaum et al. 2015a). The nowcast includes both a moderate-hazard level to maximize

56 sensitivity and a high-hazard level to reduce the number of false alarms. LHASA combines

57 rainfall and landslide susceptibility with a heuristic decision tree. First, areas rated "very low"

58 on the Landslide Susceptibility Map of Central America and the Caribbean Islands (Kirschbaum

59 et al. 2015b) are excluded from further analysis. Second, a 60-day antecedent rainfall index is

60 calculated from TMPA-RT. Third, the current daily rainfall accumulation is compared to 1 of 2

61 climatological thresholds, depending upon the level of antecedent rainfall. LHASA was

62 calibrated over the period 2007-2013 with reference to the Global Landslide Catalog (GLC), an

63 inventory of rainfall-triggered landslides reported by media and other sources (Kirschbaum et

64 al. 2015c, 2010). LHASA was validated by the GLC events occurring in 2014. 


\section{Methods}

67 LHASA was developed and calibrated with TMPA-RT precipitation estimates, but the transition

68 from TRMM to GPM required that the model be updated to use IMERG-L inputs, which do not

69 currently have the long record needed for development of the necessary rainfall-landslide

70 relations. The quantile mapping technique was accomplished in four main steps: 1) evaluation

71 of data time series and characteristics, 2) selection of space-time domain, 3) quantile

72 calculations, and 4) quantile mapping through LHASA case study. Nearly 17 years of TMPA-RT

73 and 1.2 years of IMERG-L were available for this case study.

75 First, the characteristics of each dataset were considered. Both products are produced at a

76 moderate spatial resolution, but the finer resolution of IMERG-L is associated with higher

77 precipitation estimates for extreme events, as expected. Land and sea pixels exhibit distinct

78 rainfall patterns in both IMERG-L and TMPA-RT. The relationship between products is spatially

79 heterogeneous on land (Figure 1), is not controlled solely by elevation, and is likely to be

80 difficult to predict on the basis of other variables.

82 Second, the selection of a space-time domain on which to perform quantile mapping is

83 necessarily a compromise between sample size and the relevance of the empirical distributions

84 to a specific time and place (Reichle and Koster 2004; Voisin et al. 2010). The short time period 
85 for which IMERG-L is available, combined with the relatively homogeneous time series,

86 suggested that calculation of separate monthly quantiles would reduce the sample size, without

87 making the data transformation much more representative of each month. Therefore, all data

88 from 6 May 2015 to 5 May 2016 were assigned to the same domain. Spatial heterogeneity of

89 precipitation estimates across the region implied that it would be beneficial to partition the

90 data before quantile mapping, but the absence of strong ties between the difference maps and

91 elevation, land cover, or standard climate zones made it difficult to do so on an a priori basis.

92 More importantly, LHASA focuses on extreme rainfall events. This upper tail of the distribution

93 is best described by a large sample. Therefore, the entire land area was assigned to single

94 domain. Marine pixels were not included, because these are not representative of rainfall on

95 land.

96

97 Third, 100,000 quantiles were calculated for the TMPA-RT and IMERG-L products in the

98 statistical software R (R Core Team 2015; Hijmans 2015). The large number of quantiles (1

99 cutpoint for every $0.001 \%$ of each distribution) approximated the empirical CDF and minimized

100 the error associated with interpolation of extreme rainfall. Then the quantiles for IMERG-L and

101 TMPA-RT were paired into a single table that described the whole land area over 1 year. Fourth,

102 the table was applied to each LHASA daily rainfall threshold (based on TMPA-RT) to produce

103 equivalent IMERG-L thresholds (Figure 2). These four steps were repeated for values of the 60-

104 day antecedent rainfall index.

105 
106 Fourth, the quantile-mapped version of LHASA was run with IMERG-L data. The performance of

107 the adapted rainfall thresholds was evaluated by a comparison to the original TMPA-based

108 model. The true positive rate (TPR) was determined by calculating the proportion of reported

109 landslide events (GLC) that were predicted correctly by LHASA. There may be some error in the

110 reported dates of GLC events (Kirschbaum et al. 2015c). To address this issue, TPR was

111 calculated for 1-day, 3-day, and 7-day windows (e.g. if LHASA correctly predicted a landslide

112 that occurred 2 days before its reported date, it would be counted as a true positive only for

113 the 7-day window). The number of pixel-days for which a nowcast was issued without a GLC

114 event were divided by the total number of pixel-days to determine the false positive rate (FPR).

115 These results were also compared to the LHASA calibration period.

117 Results

118 In general, the version of LHASA with IMERG-adapted thresholds remained very similar to the

119 TMPA version. Figure 3 shows the TMPA rainfall thresholds (a) and the new IMERG thresholds

120 (b). The magnitude of the change was greatest in the wettest locations due to differences in

121 calibration, the shift to finer resolution, or both. Model performance with IMERG-L was

122 comparable to TMPA-RT for both the high-hazard and moderate-hazard nowcasts (Table 2). The

123 FPR was consistent across inputs, due to the fact that quantile mapping maintains the

124 frequency with which a threshold will be exceeded. Although better results were obtained

125 during the model calibration period (2007-2013), TMPA-RT and IMERG-L produced comparable

126 postcalibration performance. 
128 Although the overall performance was good (Table 2), the high-hazard model run with IMERG-L 129 produced a FPR over 20\% in San José, Costa Rica. The anomaly did not occur elsewhere and was

130 caused by the fact that the IMERG record shows unusually frequent and heavy rainfall in the

131 Costa Rican capital (Figure 4) compared to the nearby site of El Bosque, as well as the entire

132 region. Thus, the single Central American domain was not representative of the relationship 133 between IMERG and TMPA at this site, and quantile mapping did not correct the local bias.

135 Discussion

136 LHASA showed comparable performance for IMERG and TMPA inputs, which suggests that 137 quantile mapping successfully adapted the model to the new precipitation data stream. It is 138 anticipated that subsequent versions of IMERG will further improve the precipitation estimates, 139 particularly for extreme rainfall. However, performance varied locally. Anomalous locations 140 may be poorly served by quantile mapping across a single time-space domain. If the application 141 were focused on such a location, quantile mapping should be applied more locally.

143 In other study areas and for other applications, it may be appropriate to use a different quantile 144 mapping scheme. In cases where a large amount of data is available and the relationship 145 between TMPA and IMERG varies seasonally, it may be helpful to segment the data by month 146 or season before quantile mapping (e.g. Turkington et al. 2016; Wood et al. 2004). In cases with 147 little to no seasonal variation, it may be appropriate to include partial years in the precipitation 
148 distribution. The land surface could be divided into elevation or climate zones, if these features

149 were consistently associated with biases in the precipitation data. In cases with a high degree of 150 spatial heterogeneity, it may be necessary to treat each pixel separately (e.g. Wood et al. 2004;

151 Voisin et al. 2010), which would require numerous data transformations and a sufficient

152 temporal record at each point. Another approach is to calculate quantiles within a spatial

153 sampling window (Reichle and Koster 2004). In some cases, there may be too little data that is

154 relevant to the research topic; these studies may require a more sophisticated approach than

155 quantile mapping.

157 Conclusions

158 Quantile mapping can adapt IMERG data for applications that were designed to use TMPA 159 precipitation estimates. In Central America, a daily landslide hazard model was adapted for use 160 with IMERG data by quantile mapping across a single domain. The results were comparable to 161 those for the original TMPA-based model. It is likely that other long-term precipitation datasets 162 would benefit from the same treatment. However, this method may be more successful with

163 threshold-based models and could be impacted by low sample size at the most extreme

164 precipitation values. Another key limitation of the method is that it must be applied over a

165 space-time domain with a consistent relationship between TMPA and IMERG. If this

166 requirement cannot be met, a more sophisticated treatment of the data may be required.

167 Ultimately, a longer IMERG record will obviate the need for this technique, because the user 168 community will be able to develop new climatological datasets directly from IMERG. 
170 Acknowledgements

171 NASA's GPM mission funded this research. Yudong Tian and Bin Yong provided many helpful

172 comments. We also gratefully acknowledge the reviewers of this article for their helpful

173 feedback.

174

175 References

176 Cannon, A. J., S. R. Sobie, and T. Q. Murdock, 2015: Bias Correction of GCM Precipitation by

177 Quantile Mapping: How Well Do Methods Preserve Changes in Quantiles and Extremes? J.

178 Clim., 28, 6938-6959, doi:10.1175/JCLI-D-14-00754.1.

179 http://journals.ametsoc.org/doi/full/10.1175/JCLI-D-14-00754.1\# (Accessed May 2, 2016).

180 Gudmundsson, L., J. B. Bremnes, J. E. Haugen, and T. Engen Skaugen, 2012: Technical Note:

181 Downscaling RCM precipitation to the station scale using quantile mapping - a comparison

182 of methods. Hydrol. Earth Syst. Sci. Discuss., 9, 6185-6201, doi:10.5194/hessd-9-6185-

183 2012. http://www.hydrol-earth-syst-sci-discuss.net/9/6185/2012/.

184 Hijmans, R. J., 2015: raster: Geographic Data Analysis and Modeling. R package version 2.4-15.

185 http://cran.r-project.org/package=raster.

186 Hou, A. Y., and Coauthors, 2014: The Global Precipitation Measurement Mission. Bull. Am.

187 Meteorol. Soc., 95, 701-722, doi:10.1175/BAMS-D-13-00164.1.

188 http://journals.ametsoc.org/doi/abs/10.1175/BAMS-D-13-00164.1. 
189 Huffman, G. J., 2016a: GPM (IMERG) Late Precipitation L3 1 day 0.1 degree x 0.1 degree V03. 190 ftp://jsimpson.pps.eosdis.nasa.gov/ (Accessed May 24, 2016).

$191--, 2016 \mathrm{~b}:$ TRMM (TMPA) Real-Time Precipitation L3 1 day 0.1 degree $x 0.1$ degree V07. $192 \mathrm{ftp}: / /$ trmmopen.gsfc.nasa.gov/pub/gis/ (Accessed July 17, 2016).

193 - - , and Coauthors, 2007: The TRMM Multisatellite Precipitation Analysis (TMPA): Quasi-

194 Global, Multiyear, Combined-Sensor Precipitation Estimates at Fine Scales. J.

$195 \quad$ Hydrometeorol., 8, 38-55, doi:10.1175/JHM560.1.

$196--$, R. F. Adler, D. T. Bolvin, and E. J. Nelkin, 2010: The TRMM Multi-satellite Precipitation 197 Analysis (TMPA). Satellite Rainfall Applications for Surface Hydrology, F. Hossain and M. 198 Gebremichael, Eds., Springer Verlag, 3-22.

199 - -, D. T. Bolvin, D. Braithwaite, K. Hsu, R. J. Joyce, and P. Xie, 2015: Algorithm Theoretical 200 Basis Document (ATBD) for NASA Global Precipitation Measurement (GPM) Integrated 201 Multi-satellitE Retrievals for GPM (IMERG). 30 pp.

202 Kirschbaum, D. B., R. F. Adler, Y. Hong, S. Hill, and A. Lerner-Lam, 2010: A global landslide 203 catalog for hazard applications: Method, results, and limitations. Nat. Hazards, 52, 561$204 \quad 575$, doi:10.1007/s11069-009-9401-4.

$205--$, T. Stanley, and J. Simmons, 2015a: A dynamic landslide hazard assessment system for 206 Central America and Hispaniola. Nat. Hazards Earth Syst. Sci., 15, 2257-2272, 207 doi:10.5194/nhess-15-2257-2015. http://www.nat-hazards-earth-syst208 sci.net/15/2257/2015/nhess-15-2257-2015.html (Accessed November 10, 2015). 
$209--,--$, and S. Yatheendradas, 2015b: Modeling Landslide Susceptibility over Large Regions

210 with Fuzzy Overlay. Landslides, doi:10.1007/s10346-015-0577-2.

211 http://link.springer.com/article/10.1007/s10346-015-0577-2.

$212--,--$, and Y. Zhou, 2015c: Spatial and temporal analysis of a global landslide catalog.

213 Geomorphology, 249, 4-15, doi:10.1016/j.geomorph.2015.03.016.

214 http://www.sciencedirect.com/science/article/pii/S0169555X15001579.

$215--$, and Coauthors, 2016: NASA's Remotely-sensed Precipitation: A Reservoir for Applications 216 Users. Bull. Am. Meteorol. Soc., In review.

217 Kucera, P. A., E. E. Ebert, F. J. Turk, V. Levizzani, D. Kirschbaum, F. J. Tapiador, A. Loew, and M.

218 Borsche, 2013: Precipitation from space: Advancing earth system science. Bull. Am.

219 Meteorol. Soc., 94, 365-375, doi:10.1175/BAMS-D-11-00171.1.

220 http://journals.ametsoc.org/doi/full/10.1175/BAMS-D-11-00171.1.

221 Maraun, D., 2013: Bias Correction, Quantile Mapping, and Downscaling: Revisiting the Inflation

222 Issue. J. Clim., 26, 2137-2143, doi:10.1175/JCLI-D-12-00821.1.

223 http://journals.ametsoc.org/doi/abs/10.1175/JCLI-D-12-00821.1 (Accessed May 4, 2016).

224 R Core Team, 2015: R: A language and environment for statistical computing. http://www.r$225 \quad$ project.org/.

226 Reichle, R. H., and R. D. Koster, 2004: Bias reduction in short records of satellite soil moisture.

227 Geophys. Res. Lett., 31, doi:10.1029/2004GL020938.

228 http://onlinelibrary.wiley.com/doi/10.1029/2004GL020938/full. 
229 Turkington, T., A. Remaître, J. Ettema, H. Hussin, and C. van Westen, 2016: Assessing debris

230 flow activity in a changing climate. Clim. Change, 0, 1-16, doi:10.1007/s10584-016-1657-6.

231 http://link.springer.com/article/10.1007/s10584-016-1657-6.

232 Voisin, N., J. C. Schaake, and D. P. Lettenmaier, 2010: Calibration and Downscaling Methods for

233 Quantitative Ensemble Precipitation Forecasts. Weather Forecast., 25, 1603-1627,

234 doi:10.1175/2010WAF2222367.1.

235 Ward, A., and D. Kirschbaum, 2014: Measuring Rain for Society's Gain: GPM Applications

236 Workshop. NASA Earth Obs., 26, 4-11.

$237--,--$, and M. Hobish, 2015: Measuring Rain and Snow for Science and Society: The Second 238 GPM Applications Workshop. Earth Obs., 27, 4-11.

239 Wood, A. W., L. R. Leung, V. Sridhar, and D. P. Lettenmaier, 2004: Hydrologic implications of 240 dynamical and statistical approaches to downscaling climate model outputs. Clim. Change, $241 \quad 62,189-216$, doi:10.1023/B:CLIM.0000013685.99609.9e.

242 http://link.springer.com/article/10.1023/B:CLIM.0000013685.99609.9e\#enumeration. 


\section{Tables}

245 Table 1: Summary of TRMM and GPM multi-satellite products, resolutions, availability and

246 latency. The TRMM Level 3 multi-satellite product TMPA has a near real-time version that is

247 calibrated with a gauge climatology and a research product that uses a global network of

248 gauges to calibrate the product. GPM Level 3 IMERG has three versions: the early run is

249 produced with a latency of $\sim 5$ hours after satellite acquisition. The late run uses more satellite

250 information and an improved morphing scheme, and a final run uses a global gauge network to

251 calibrate the observations.

\begin{tabular}{|c|c|c|c|c|c|c|}
\hline \multirow{2}{*}{ Satellite } & \multirow{2}{*}{$\begin{array}{l}\text { Algorithm } \\
\text { Name }\end{array}$} & \multicolumn{2}{|c|}{ Resolution } & \multirow{2}{*}{ Coverage } & \multirow{2}{*}{ Available } & \multirow{2}{*}{ Latency } \\
\hline & & Space & Time & & & \\
\hline \multirow[b]{2}{*}{ TRMM } & \multirow{2}{*}{$\begin{array}{l}\text { TRMM Multi- } \\
\text { Satellite } \\
\text { Precipitation } \\
\text { Analysis (TMPA } \\
\text { Version 7) }\end{array}$} & \multirow{2}{*}{$\begin{array}{c}0.25^{\circ} \\
x \\
0.25^{\circ}\end{array}$} & \multirow[b]{2}{*}{3 hours } & \multirow{2}{*}{$\begin{array}{c}\text { Gridded, } \\
50^{\circ} \mathrm{N}- \\
50^{\circ} \mathrm{S}\end{array}$} & $\begin{array}{c}2000- \\
\text { present }\end{array}$ & 8 hours (Real time) \\
\hline & & & & & $\begin{array}{l}1998 \text { to } \\
\text { present }\end{array}$ & 2 months (Research) \\
\hline \multirow{3}{*}{ GPM } & \multirow{3}{*}{$\begin{array}{c}\text { Integrated } \\
\text { Multi-satellitE } \\
\text { Retrievals for } \\
\text { GPM (IMERG) }\end{array}$} & \multirow{3}{*}{$\begin{array}{l}0.1^{\circ} \mathrm{x} \\
0.1^{\circ}\end{array}$} & \multirow{3}{*}{$\begin{array}{c}30 \\
\text { minutes }\end{array}$} & \multirow{3}{*}{$\begin{array}{c}\text { Gridded, } \\
65^{\circ} \mathrm{N}- \\
65^{\circ} \mathrm{S}\end{array}$} & $\begin{array}{c}\text { April 2015- } \\
\text { present }\end{array}$ & 5 hours (Early run) \\
\hline & & & & & $\begin{array}{l}\text { March } \\
\text { 2015- } \\
\text { present }\end{array}$ & 15 hours (Late run) \\
\hline & & & & & $\begin{array}{c}\text { March } \\
\text { 2014- } \\
\text { Present }\end{array}$ & $\begin{array}{l}3.5 \text { months (Final } \\
\text { run) }\end{array}$ \\
\hline
\end{tabular}

252

253 Table 2: The performance of TMPA-RT and IMERG-L was compared by determining the number

254 of landslides predicted by each model run. This table shows: (a) precipitation product ; (b)

255 corresponding date range; (c) version of LHASA that was tested (d) number of landslides

256 reported during each time period; (e)-(g) proportion of landslides for which a nowcast was 
257 issued on the reported date (1-day), the day before or after the reported event (3-day), and

258 within a 7-day window around the reported date, respectively; and (h) FPR or overall frequency

259 with which LHASA issues nowcasts at dates and places without recorded landslides.

\begin{tabular}{|c|c|c|c|c|c|c|c|}
\hline $\begin{array}{c}\text { a. Model } \\
\text { input }\end{array}$ & $\begin{array}{c}\text { b. Date } \\
\text { range of } \\
\text { model run }\end{array}$ & $\begin{array}{c}\text { c. Hazard } \\
\text { Level }\end{array}$ & $\begin{array}{c}\text { d. } \\
\text { Landslide } \\
\text { Reports }\end{array}$ & $\begin{array}{c}\text { e. 1- } \\
\text { day } \\
\text { TPR }\end{array}$ & $\begin{array}{c}\text { f. 3- } \\
\text { day } \\
\text { TPR }\end{array}$ & $\begin{array}{c}\text { g. 7- } \\
\text { day } \\
\text { TPR }\end{array}$ & h. FPR \\
\hline TMPA-RT & $2007-2013$ & Moderate & 99 & $64 \%$ & $77 \%$ & $83 \%$ & $11 \%$ \\
\hline TMPA-RT & 2014 & Moderate & 43 & $58 \%$ & $74 \%$ & $79 \%$ & $9 \%$ \\
\hline TMPA-RT & $\begin{array}{c}5 / 2015- \\
5 / 2016\end{array}$ & Moderate & 73 & $45 \%$ & $73 \%$ & $84 \%$ & $6 \%$ \\
\hline IMERG-L & $\begin{array}{c}5 / 2015- \\
5 / 2016\end{array}$ & Moderate & 73 & $56 \%$ & $73 \%$ & $82 \%$ & $10 \%$ \\
\hline TMPA-RT & $2007-2013$ & High & 99 & $26 \%$ & $37 \%$ & $47 \%$ & $1 \%$ \\
\hline TMPA-RT & 2014 & High & 43 & $12 \%$ & $33 \%$ & $47 \%$ & $1 \%$ \\
\hline TMPA-RT & $\begin{array}{c}5 / 2015- \\
5 / 2016\end{array}$ & High & 73 & $15 \%$ & $29 \%$ & $37 \%$ & $1 \%$ \\
\hline IMERG-L & $\begin{array}{c}5 / 2015- \\
5 / 2016\end{array}$ & High & 73 & $12 \%$ & $40 \%$ & $49 \%$ & $1 \%$ \\
\hline
\end{tabular}

260 


\section{Figure Caption List}

263 Figure 1: Difference between TMPA-RT (regridded to $0.1^{\circ}$ ) and IMERG-L from March 7, 2015 to

264 March 6, 2016 for the daily a) $75^{\text {th }}$ and b) $95^{\text {th }}$ percentiles. Positive values indicate areas where

265 TMPA-RT is higher (blue) and negative areas show that IMERG-L is higher (red). At these

266 percentiles, no difference was observed in many arid regions, but differences can be observed in

267 those regions during rare precipitation events.

268 Figure 2: Quantile-quantile plot for the Central American land area for May 6, 2015-May 5,

269 2015. 100,000 quantiles (open circles) were calculated for the TMPA-RT and IMERG-L rainfall

270 estimates. In quantile mapping, a value from one product is used to look up the value of the

271 second product at the same quantile. For example, if a TMPA-RT precipitation threshold were

$272180 \mathrm{~mm}$ day $^{-1}$, the equivalent IMERG-L value would be $231 \mathrm{~mm}^{\text {day }}{ }^{-1}$.

273 Figure 3: (a) The LHASA high-hazard rainfall threshold was calculated from TMPA-RT data for

274 the period 2001-2014. (b) The quantile-mapped IMERG-L equivalent thresholds.

275 Figure 4: Quantile-quantile plot of two locations in Costa Rica, as well as the whole of Central

276 America (black). Dry days are not shown. El Bosque (blue) is separated from San José (red) by

277 approximately 45 kilometers, but the observed relationship between IMERG-L and TMPA-RT is

278 dramatically different. The capital of Costa Rica has an anomalous IMERG record, in which

279 precipitation is both heavier and more frequent. 


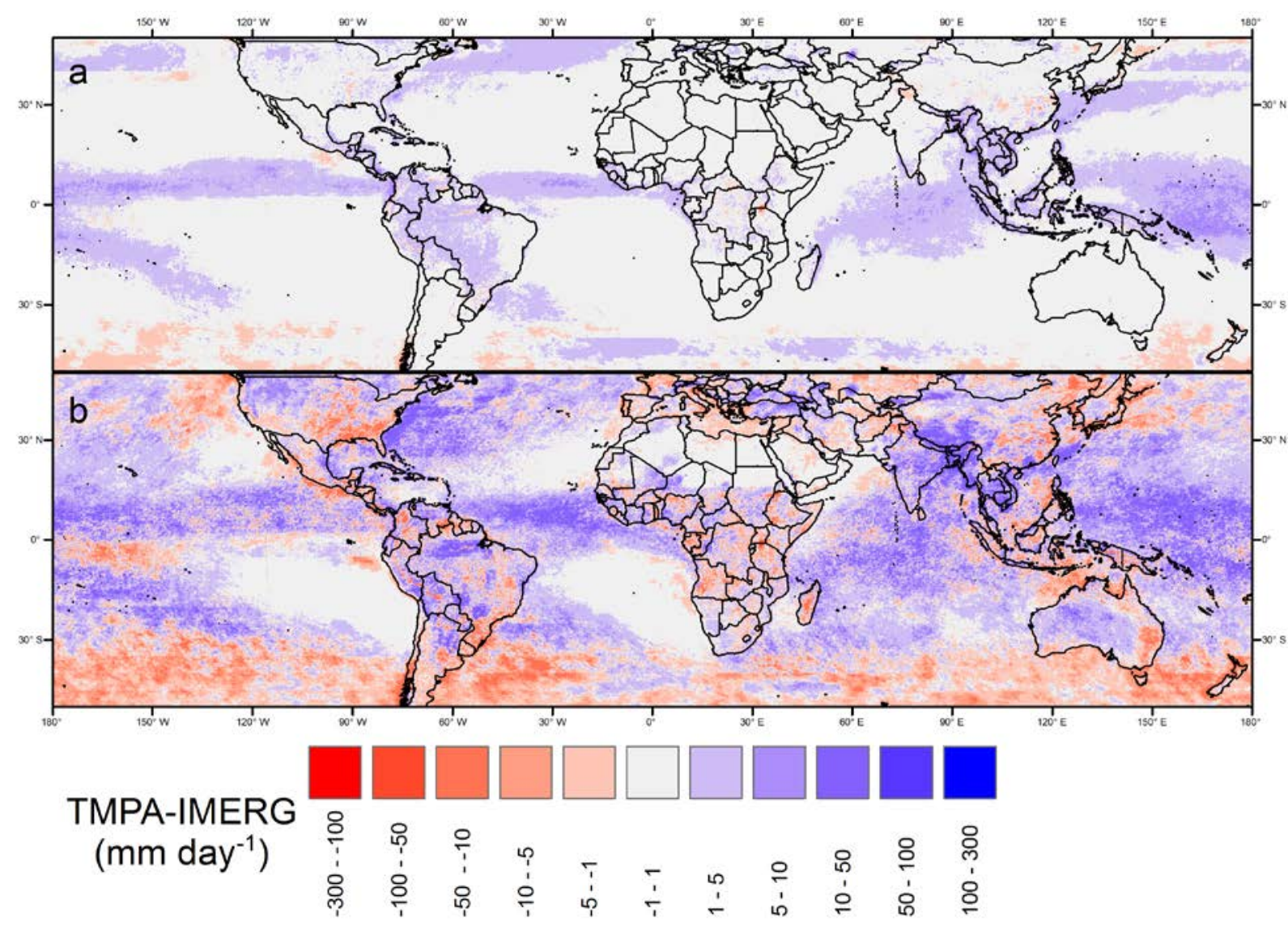

283 Figure 1: Difference between TMPA-RT (regridded to 0.1 ${ }^{\circ}$ ) and IMERG-L from March 7, 2015 to

284 March 6, 2016 for the daily a) $75^{\text {th }}$ and b) $95^{\text {th }}$ percentiles. Positive values indicate areas where

285 TMPA-RT is higher (blue) and negative areas show that IMERG-L is higher (red). At these

286 percentiles, no difference was observed in many arid regions, but differences can be observed in

287 those regions during rare precipitation events. 


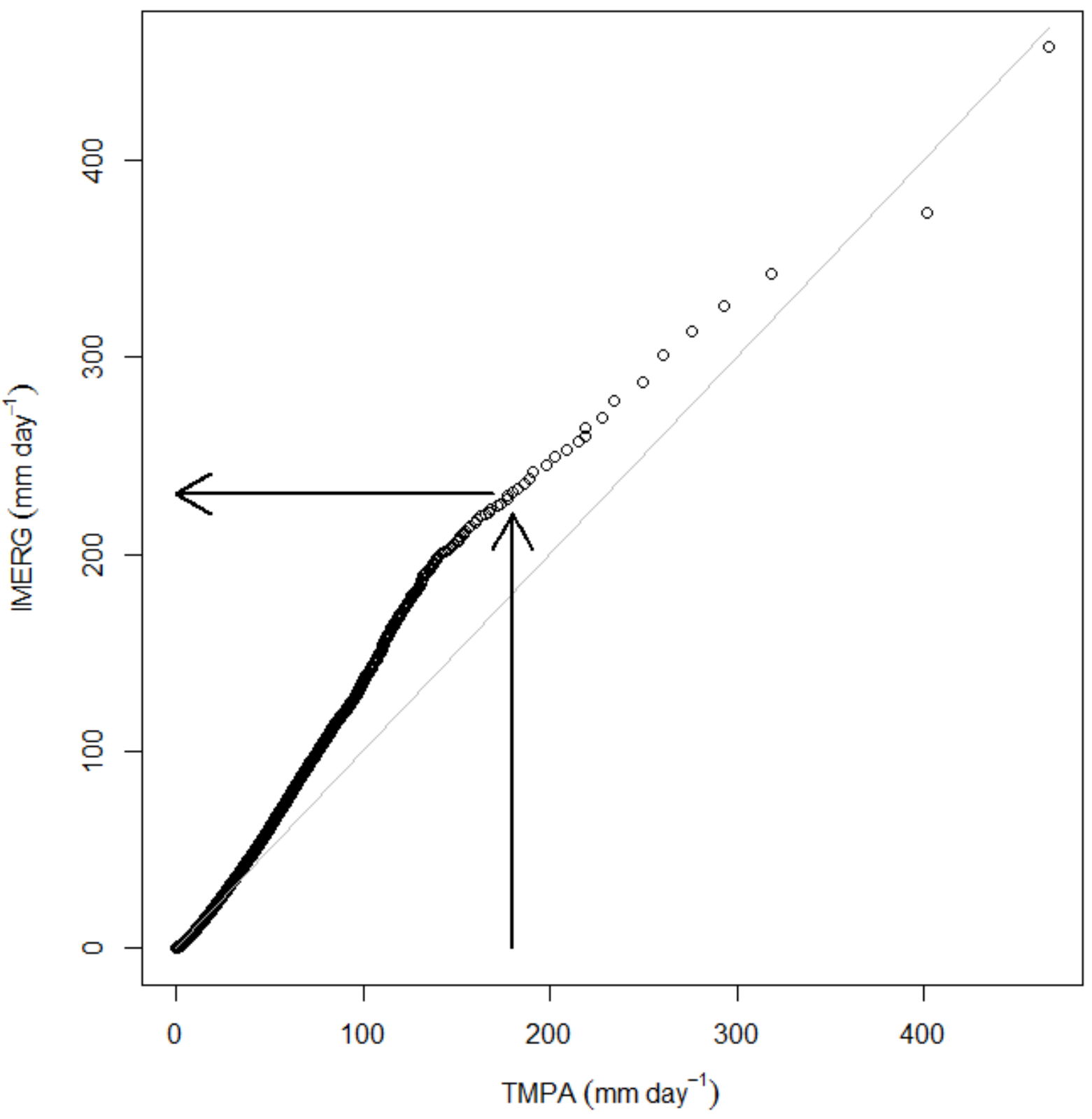

290 Figure 2: Quantile-quantile plot for the Central American land area for May 6, 2015-May 5,

291 2015. 100,000 quantiles (open circles) were calculated for the TMPA-RT and IMERG-L rainfall

292 estimates. In quantile mapping, a value from one product is used to look up the value of the 
293 second product at the same quantile. For example, if a TMPA-RT precipitation threshold were

$294180 \mathrm{~mm} \mathrm{day}^{-1}$, the equivalent IMERG-L value would be $231 \mathrm{~mm}$ day $^{-1}$.

295

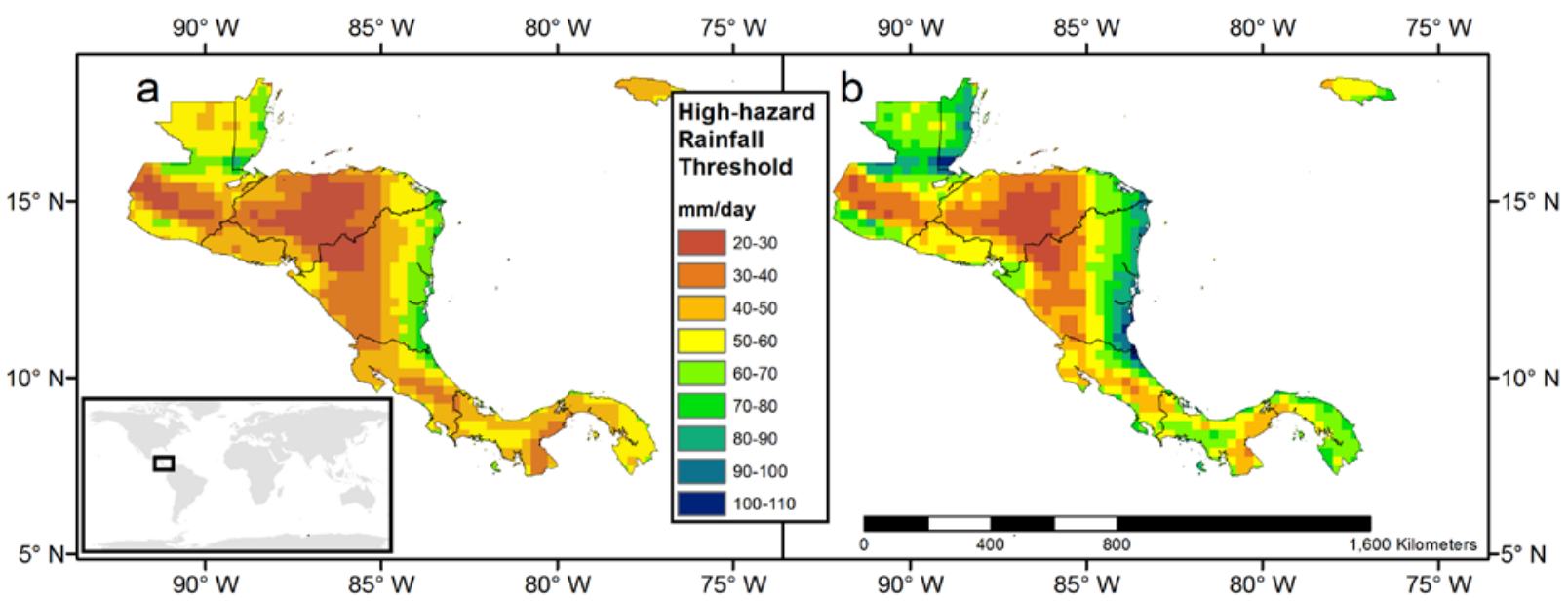

297 Figure 3: The LHASA high-hazard rainfall threshold was calculated from a) TMPA-RT data for the 298 period 2001-2014, b) the quantile-mapped IMERG-L equivalent thresholds.

299
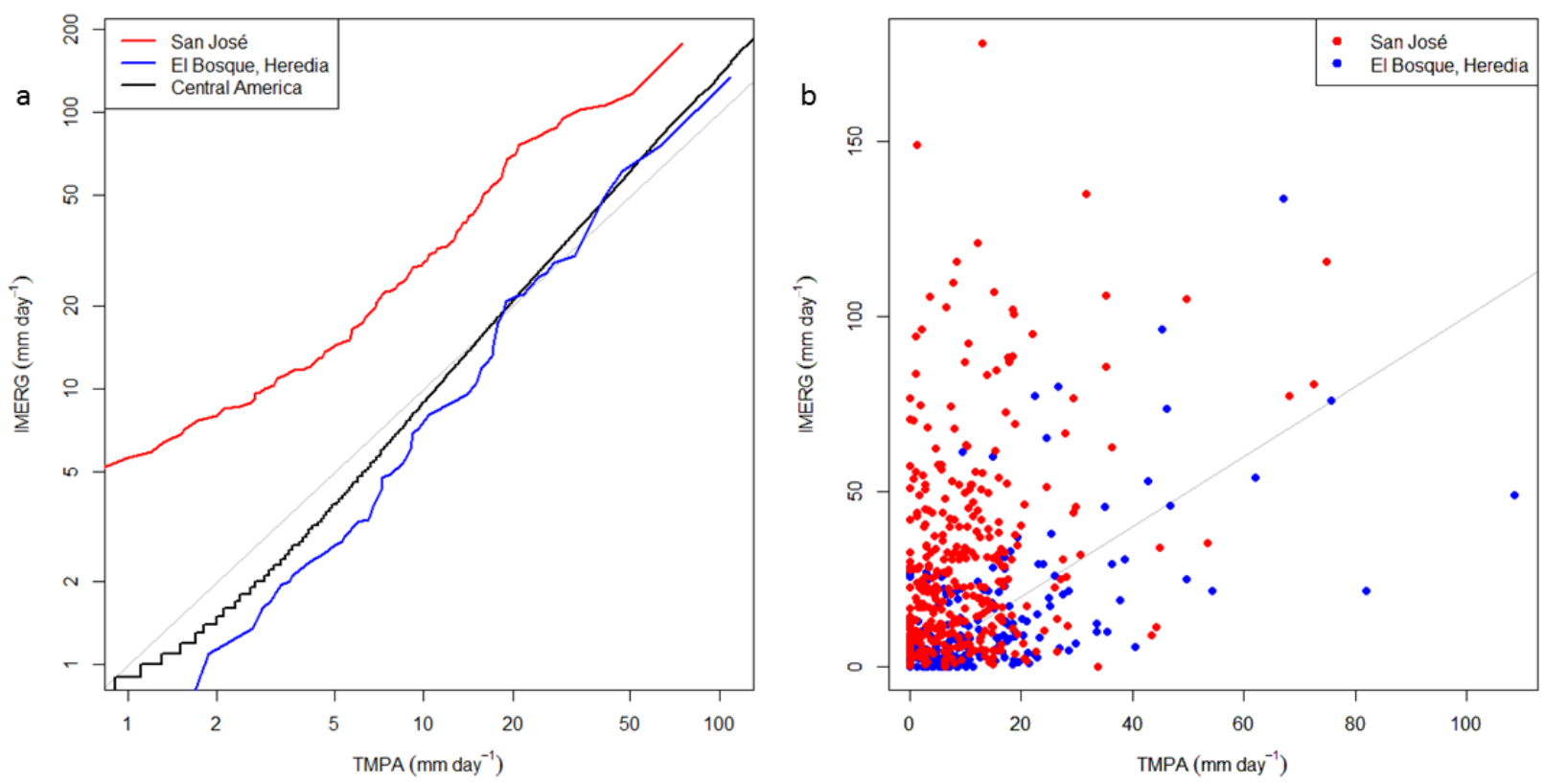

300 
301 Figure 4: a) Quantile-quantile plot of two locations in Costa Rica, as well as the whole of Central 302 America (black). Dry days are not shown. El Bosque (blue) is separated from San José (red) by 303 approximately 45 kilometers, but the observed relationship between IMERG-L and TMPA-RT is 304 dramatically different. b) The capital of Costa Rica has an anomalous IMERG record, in which 305 precipitation is both heavier and more frequent. 